\title{
Contrast enhanced magnetic resonance angiography in children: initial experience at 3.0 Tesla
}

SN Khan ${ }^{1}$, C Meehan $^{1}$, A Plotnik ${ }^{1}$ I Ayad ${ }^{2}$, S Patel ${ }^{2}$, I Boechat ${ }^{1}$, P Finn ${ }^{1 *}$

From 16th Annual SCMR Scientific Sessions

San Francisco, CA, USA. 31 January - 3 February 2013

\section{Background}

To assess the role of contrast enhanced magnetic resonance angiography (CEMRA) at 3.0T in pediatric patients referred for vascular evaluation, and to compare the technical and diagnostic performance of a clinically similar control group at $1.5 \mathrm{~T}$.

\section{Methods}

Fifty pediatric patients referred for vascular evaluation and without evidence of congenital heart disease, were evaluated with CEMRA. Thirty-five patients received 37 studies

at 3.0T (age $0.4-16.5$ years, mean $5.8 \pm 4.7$ years. Fifteen patients received 16 studies at $1.5 \mathrm{~T}$ (age $0.1-17.5$ years, mean $5.8 \pm 6.4$ years). CEMRA was performed in three phases: arterial, early venous and late venous. Two independent observers analyzed the studies for image quality, artifacts and vessel definition.

\section{Results}

Overall image quality and vessel definition scores were higher at $3.0 \mathrm{~T}$ than $1.5 \mathrm{~T}$ in the arterial and early venous phase, however not the late venous phase. Overall

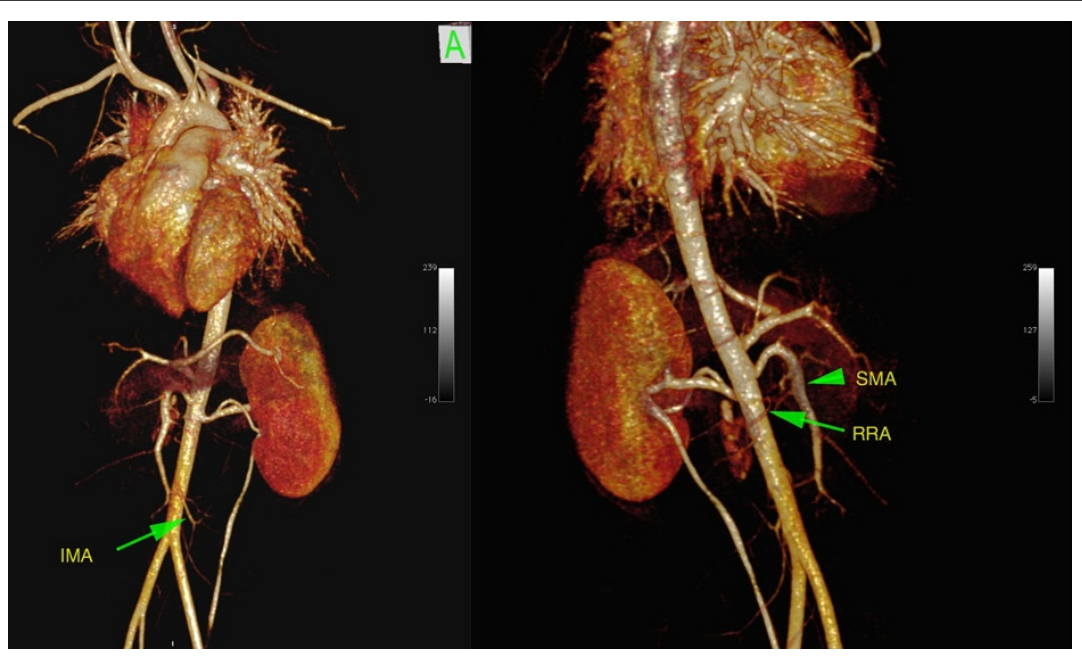

Figure 19 year old male with right vestigial kidney, contrast enhanced MRA performed at 3.0T. Left, 3D volume rendered reconstruction, anterior view, IMA = inferior mesenteric artery. Right, 3D volume rendered reconstruction, posterior view, SMA = superior mesenteric artery, RRA = right renal artery.

Radiology, UCLA, Los Angeles, CA, USA

Full list of author information is available at the end of the article

(c) 2013 Khan et al; licensee BioMed Central Ltd. This is an Open Access article distributed under the terms of the Creative Commons 
diagnostic performance was comparable at both field strengths. Breathing, pulsation and parallel acquisition artifact was found to some extent in all phases, but ventilated patients received significantly higher image quality scores and vessel definition scores than conscious patients.

\section{Conclusions}

CEMRA at $3.0 \mathrm{~T}$ and $1.5 \mathrm{~T}$ produces diagnostic quality studies for pre-and post-transplantation vascular assessment in pediatric patients. For optimum image quality and spatial resolution, the use of 3.0T MRA with controlled ventilation is recommended if readily available.

\section{Funding}

Siemens Research Grant.

\section{Author details}

${ }^{1}$ Radiology, UCLA, Los Angeles, CA, USA. ${ }^{2}$ Anesthesia, UCLA, Los Angeles, CA, USA.

Published: 30 January 2013

- Convenient online submission

- Thorough peer review

- No space constraints or color figure charges

- Immediate publication on acceptance

- Inclusion in PubMed, CAS, Scopus and Google Scholar

- Research which is freely available for redistribution 